\title{
PHOTODYNAMIC THERAPY: INCEPTION TO APPLICATION IN BREAST CANCER
}

Authors: S. M. Banerjee ${ }^{1,2}$, A.J MacRobert ${ }^{2}$, C. A. Mosse ${ }^{2}$, B. Periera ${ }^{1}$, S.G. Bown ${ }^{2}$, and M.R.S. Keshtgar ${ }^{1,2 *}$

Institution(s) - (1) Royal Free London NHS Foundation Trust

(2) Division of Surgery and interventional Science, University College London

Corresponding Author: Prof. M.R.S. Keshtgar, Professor of Surgical Oncology, Address: Royal Free London NHS Foundation Trust, Pond street, Hampstead, London NW3 2QG.

Email: m.keshtgar@ucl.ac.uk 


\section{Abstract}

Photodynamic therapy (PDT) is already being used in the treatment of many cancers. This review examines its components and the new developments in our understanding of its immunological effects as well as pre-clinical and clinical studies, which have investigated its potential use in the treatment of breast cancer.

KEY WORDS: breast cancer, photodynamic therapy 


\section{Background}

Breast cancer is the most common cancer to affect women worldwide [1] and over 50,000 new cases are diagnosed each year in the UK effecting 1 in 8 women [1,2]. Although mortality from breast cancer is falling particularly in the developed countries its incidence is rising [2-5]. With the advent of breast screening more cancers are diagnosed early and therefore often require less extensive surgical treatment when combined with adjuvant therapies. The use of novel technologies to treat all stages of breast cancer is desirable because they allow greater options to be available for all patients including those who are not eligible for standard management. However in order to be successful they need to offer additional benefits or less side effects when compared to the standard of care. In this article Photodynamic therapy (PDT) is reviewed with regard to the components that make it a successful therapy and the new developments in our understanding of its immunological effects. New evidence suggests that PDT has the potential to induce immunity against recurrence and destruction of metastases distant from the treated sites, with minimal sideeffects, provides additional advantages over existing treatments.

The successful use of PDT as a therapy [23] requires the optimum combination of light of a specific wavelength, a light-activated chemical substance known as a photosensitiser and molecular oxygen present in the tissue to elicit cell death through oxidative damage [6]. The basis of treatment is dependent on uptake of the photosensitiser into malignant tissue following systemic or topical administration. Once the optimum tissue concentration is achieved, the malignant tissue can then be exposed to low power visible light for a pre- 
determined time for the treatment to be effective (see Fig.1). In most cases the spectral output of the light source is matched to the absorption spectrum of the photosensitiser in order to optimize the photosensitiser activation. The absorption of light by the photosensitiser elevates the molecule from its ground state $\left(S_{0}\right)$ to an excited electronic state $\left(S_{1}\right)$ (Fig.2). Subsequently there is rapid transition from the singlet $S_{1}$ state to a longlived triplet $\mathrm{T}_{1}$ excited state. The photosensitiser can then transfer its internal excited state energy to an oxygen molecule to generate 'singlet oxygen', a powerful cytotoxic oxidizing species [7]. Optimum wavelengths for tissue light transmission lie between $600-800 \mathrm{~nm}$ $[8,9]$. Across this range the major components of living tissue, namely water, haemoglobin in blood and protein have low absorption allowing more efficient light transmission through tissue (Fig.3). In addition to singlet oxygen generation via energy transfer (the Type 2 mechanism), a Type 1 mechanism based on electron transfer between the triplet state and biomolecules can also operate. This leads to superoxide anion and other reactive oxygen (ROS) formation (see fig 2) [10]. ROS such as singlet oxygen, hydroxyl radicals and superoxide anions result in oxidative cell damage and can promote apoptosis (programmed cell death) or necrosis depending on the intensity of light delivered. Photo-oxidative damage is known to occur to key molecules associated with the cell membrane function including amino-acid residues and cholesterol as well as intra-cellular structures including nucleic acids, which control normal cellular activity and its relative state within the cell cycle. A critical level of damage to these key structures usually triggers a cascade of cellular events leading to irreversible cellular damage apoptosis and tissue necrosis [11-18] as its primary effect. 


\section{Photosensitisers}

The ideal characteristics of the photosensitiser include minimal dark toxicity, with rapid selective metabolism and/or clearance from healthy tissue, until the optimum tissue concentration has been reached in the malignant tissue, with minimal side effects [6]. One factor that might facilitate this process is the leaky vasculature present in tumours combined with poorer lymphatic drainage. Therefore tumours can preferentially retain a larger concentration of the photosensitizer when administered intravenously compared to normal tissue. The ideal light dose is one that it can effectively activate the photosensitiser causing cell death to the target tissue but not cause damage to healthy tissue. In reality however true selectivity in the light dose is not achievable, and it is instead the targeted delivery of light to known areas of disease using fibre-optic light guides while avoiding healthy tissues, which are also photosensitive, that facilitates effective treatment. New clinically used photosensitisers have strong red or near-infrared absorption and a welldefined composition with simple and stable drug formulation delivered through the intravenous route.

The structural characteristics of individual compounds have a significant role in their suitability to act as a photosensitiser [19]. Aromatic tetrapyrrolic structures are particularly suitable $[17,20]$. The first generation of commercial photosensitisers, Haematoporphrin derivative $(\mathrm{HpD}$ ) and its purified version Photofrin, were based on this structure. 
While showing efficacy as good photosensitisers and preferentially localizing within tumours, they exhibited a prolonged photosensitivity due to a long cutaneous retention half-life in patients, and poor absorption at longer red wavelengths, limiting their treatment use.

A second generation of compounds specifically designed to have minimal side-effects and overcome the undesirable qualities of their predecessors is now available which has facilitated PDT use in cancer therapy. These are an extensive group of compounds used in a wide range of therapeutic applications. In terms of cancer therapy alone this includes 5Aminolaevulinic acid (ALA), which is metabolized to a porphyrin photosensitizer, and esterified derivatives of ALA [21,22], i.e. its methyl and hexyl esters. [16,23]. Another family of compounds, phthalocyanines, has been investigated for their potential use in cancer therapy $[24,25,26]$ as well as tools to improve our understanding of how PDT exerts its effect. Since many of the most effective photosensitisers are lipophilic and are taken up avidly by cell membranes including organelle membranes, investigation of novel delivery systems to overcome poor water solubility of such compounds is being pursued $[27,28]$. An example of this is zinc phthalocyannine, which has been used recently to investigate the pathways of cell death in breast cancer cell lines exposed to PDT [29] (Table 1). This photosensitiser showed potential as therapeutic agent when delivered through albumin nanospheres with good efficacy and no adverse effects in a murine model [30]. 
Compounds used specifically in breast cancer (Table 1) for the treatment of cutaneous metastases include Visudyne ${ }^{\mathrm{TM}}$ which contains a benzoporphorin derivative monoacid ring $\mathrm{A}$ (verteporfin or BPD-MA) $[23,31,32]$, as a liposomal formulation to overcome the poor water solubility of the verteporfin photosensitiser. Advantages to using this agent in breast cancer therapy include the high tissue penetration at its peak absorption at $690 \mathrm{~nm}$, with optimum concentration in malignant tissue lasting between 30 to 150 minutes before being completely cleared at 48 hours.

Purlytin $^{\mathrm{TM}}$ (tin etiopurpurin), a chlorin photosensitiser has also been investigated for use in the treatment of cutaneous metastases of breast cancer [33]. Its structure results in a stronger absorption of light at the $650-680 \mathrm{~nm}$ range. Another group of photosensitisers, the Texaphyrins have been explored, which are expanded porphyrins with a penta-aza core that facilitates strong absorption of light in the 730-770nm range. Lutex ${ }^{\mathrm{TM}}$ (Lutetium texaphyrin) has been assessed in the treatment of breast cancer skin lesions [31]. In clinical trials texaphyrins have also been used as radio-sensitizers [11].

Standard chemotheraputic agents such as anthracyclines and anthraquinones have been examined with regard to their structural properties to assess their ability to act as photosensitisers [34,35]. Specifically Mitoxantrone a type II topoisomerase inhibitor has been investigated for their suitability as photosensitisers in order to combine their cytotoxic effects with PDT but at a lower dose compared to standard systemic chemotherapy treatment therefore incurring fewer side-effects. Additionally this may allow treatment of 
drug and radiation resistant tumour cells [36,37]. Montazerabadi et al investigated its effects as a potential photosensitiser on breast cancer cell lines and their results suggested it to be an efficient photosensitiser [36]. However other studies are not as conclusive.

Secret et al in 2013 demonstrated that porous silicon nanoparticles can also be used to covalently carry porphyrin related photosensitisers into breast cancer cells to in order to improve bioavailability for PDT treatment [38] and albumin based nanopheres and liposomes [39] have successfully used for photosensitiser delivery. However this has yet to be translated beyond cell line and animal model based studies. One of the difficulties identified with the use of nanospheres is that they are less successful at carrying the photosensitiser at high doses and retaining them in their active state [40]. The development of poly ( $\mathrm{N}$-isopropylacrylamide)- PNIPAM microgel for encapsulation of photosensitisers may lead to improved efficacy $[40,41,42]$.

Nanoparticles that are biodegradeable and include PNIPAM microgel, stabilize photosensitisers as they are able to provide protection against degradation by enzymes and the microenvironment in vivo. Khanal et al in 2014 [40] used PNIPAM to encapsulate, methylene blue, which was used as a photosensitiser against a breast cancer cell line treated with PDT. Their results confirmed improved efficacy could be achieved using this technique. 
Other novel photosensitisers that are in development for PDT, include bacteriochlorophyll derivatives, for example a water-soluble derivative (TOOKAD ${ }^{\circledR}$ Soluble) which is distributed primarily in the vasculature at the time of treatment [44]. Its application, which results in vascular occlusion following PDT has so far been limited clinically to use in the treatment of prostate cancer. TOOKAD ${ }^{\circledR}$ Soluble may be of benefit in the treatment of large breast tumours but this has not yet been investigated. In order to improve PDT selectivity and minimize destruction of normal breast tissue, various new strategies have been developed which target specific characteristics unique to the tumour and its vasculature. It had been established that selective tumour receptor tissue factor (TF)-expression is observed in almost all breast cancer tissues and that there is an association between the concentration of plasma TF and TF-expression in cancer tissues [45].

Ligand-targeted photodynamic therapy (tPDT) by conjugating factor VII (fVII) protein with photosensitiser, verteporfin has been investigated, in order to overcome the poor selectivity and enhance the effect of non-targeted PDT for cancer treatment [46]. The results show that this method of targeted PDT could selectively kill TF expressing breast cancer cells with no side effects in cells which did not express TF. It also resulted in improved effectiveness of PDT with greater degree of apoptosis and necrosis and inhibition of tumour growth in mice. Tumour cell targeting factor VII Targeted Sn(IV) chlorin e6 (SnCe6) PDT produced comparable results [47]. However there has not yet been a further extension of this 
technique into a phase I clinical trial so far but represents the future for selective tumour treatment with PDT.

\section{Mechanisms of PDT-induced Immune response}

\section{Cellular cytotoxicity mechanisms}

Direct cytotoxic effects of PDT cause oxidative stress in the endoplasmic reticulum and photo-oxidative damage to cells resulting in apoptosis and tumour necrosis [48][49][50]. Extra-cellular release of intra-cellular proteins, known as damage-associated molecular patterns (DAMPs) typically occurs 1-4 hours after PDT [48]. Various DAMPs have been identified. Heat shock proteins (HSPs), calreticulin and high mobility group box -1 (HMGB1) are examples of DAMPS, released/expressed by dead and dying cells and potentiate immune cell activation, migration to the site of cellular damage and phagocytosis of damaged cells which ultimately leads to antigen presentation and T cell activation (Fig 5) [48]. PDT related oxidative stress results in activation of transcription factors, such as nuclear factor $\mathrm{kB}$ and activator protein $1[51,52]$.

PDT results in an acute inflammatory response mediated by neutrophils, macrophages and other cellular components, which migrate to the treated tumour site $[48,53]$. Neutrophil populations are first to increase and this is facilitated by TNF-a a byproduct of PDT $[48,54]$. In addition, immediately post PDT, myloid cells, monocytes, macrophages and mast cell population, are also observed to rise [54]. The end result of this process is the activation of CD8+ T cells (Fig.5) [8]. 
While neutrophils are the first to increase in number and migrate in response to PDT macrophages also have a significant role in potentiating the immune mediated effects and are sensitive to changes to PDT dose. Macrophages appear to be preferentially activated by low dose PDT. Following PDT, macrophages secrete lysophosphatidylcholine. This protein is a substrate in a T and B cell enzymatic pathway that ultimately leads to the production of Macrophage Activation factor (MAF), and the resulting activated macrophages elicit tumour specific cytotoxic activity [48]. Furthermore PDT appears to enhance the phagocytic activity of macrophages facilitating their role in removal of dead and dying cells from the treatment site [49].

T cell mediated anti-tumour activity is central to the efficacy of PDT in both the innate and adaptive responses $[55,56,57]$. Antigen presentation by neutrophils, macrophages and dendritic cells to the T cell receptor via MHC class I protein results in CD8+ (cytotoxic) T cell activation and tumour specific cytotoxicity. Alternatively MHC class II antigen presentation by APCs results in CD4+ (helper) T cell activation (Fig.5). Further dichotomy in T cell activity is demonstrated with CD4+ T helper 1 cells responsible for activation of CD8+ cytotoxic $T$ cells while CD4+ helper 2 cells causes B cells proliferation and antibody class switching and activates macrophages [50].

\section{Cytokine and complement derived cytotoxic mechanisms}

PDT effects the complement system and cytokine production. $[48,58,59]$. Following PDT pro-inflammatory cytokines levels are increased. C3 and C5a promotes neutrophila after 
PDT. IL-6 is produced in large amounts and promotes megakaryotes and haemopoietic progentitor cells production and T cell proliferation (Fig.5) [48,56,60]. However not all cytokine activation promotes its pro-inflammatory, anti-tumour activity of PDT but excess production results in reduced efficacy in some tumours.

\section{Factors effecting PDT efficacy}

Efficacy depends on the anatomical site [61], the type of photosensitiser and dose $[48,62]$. In addition the treatment conditions, specifically low power density or fluence rates causing less oxygen depletion [63] may result in improved immune activation. A normal functioning host immune system is a pre-requisite with immune-suppression reducing the success of treatment $[48,49,50,64]$. Reduced efficacy of anti-tumour activity may be related several mechanisms. PDT mediated immune suppression occurs to counter auto- immune reactions $[48,50,64]$. PDT induced production of VEGF delays DC maturation, lead to T regulatory cell (Treg cell) mediated immune suppression.

Low levels of nitric oxide (NO) are produced by tumour cells by via nitric oxide synthetase (NOS) in response to PDT, as a cytoprotective defence. This appears, to reduce the efficacy of PDT [65]. Conversely Cox inhibitors, which block NO production improve PDT efficacy $[65,66,67]$. Furthermore $\mathrm{Nf} \mathrm{Kb}$ is also implicated in the regulation of COX-2 expression, important in PGE2 and leukotriene production. Selective COX-2 inhibition results in improved PDT efficacy by reducing negative feedback regulation of this pathway. 


\section{PDT in combination immune modulatory agents}

PDT mediated immune response, which extends to distant sites after local treatment appear to dependent on multiple factors not all of which are known, and does not occur in all cases $[56,68]$. However studies which combined PDT with an immune- stimulatory agents, have demonstrated local and distant immune responses consistently $[55,70]$.

Evidence has been presented that PDT combined with immune-modulatory agents can induce a sustained immune response and improve efficacy in tumour cell destruction and stasis in tumour growth in a number of cancer mouse models including breast cancer. $[55,70,71,72,73]$. Combination treatment caused an increased neutrophil infiltration, improvement in tumor antigen presentation, greater T-cell activation, suppressed expression of (Tregs) with effective rejection of tumor re-challenge [50]. In some cases this was independent of the choice of photosensitiser [50,71]. Recently Xia et al [72] demonstrated that a combination of PDT and immunomodulatory agent, CpG oligodeoxynucleotide, resulted in delay in metastatic spread, prolonged survival and increased activation of CD8+ T cells. Another treatment strategy used by Shams et al [73] is a two step treatment process in combination with immune enhancement, with low PDT dose (immunogenic) administered followed by high dose with variable anti-tumour efficacy in different tumour cell lines. [73]. This treatment prolonged survival and delay in metastatic spread. So Far these findings have yet to be translated into the clinical setting. 


\section{Adjuvant PDT}

Alternative avenues of PDT treatment are also being explored through cell lines and animal models. Specifically its role combined with adjuvant radiotherapy and chemotherapy for the treatment of breast cancer and its sequelae. Photosensitisers have the potential of acting as agents for combination therapy with chemotherapy or radiotherapy. Some photosensitisers have been found to be useful as radiosensitisers, with preliminary data suggesting that they could be used in the treatment of metastases in some cancers $[11,74]$, but have not been used in the treatment of breast cancer so far. However the concept of using PDT as an adjuvant to conventional radiotherapy in breast cancer treatment continues to be of interest. The effects of combined treatment with radiotherapy and PDT on breast cancer cell lines have been investigated using indocyanine green as the photosensitiser and a low dose of radiotherapy (4Gy) with encouraging results [75]. PDT effects on normal bone in vivo have been studied [76] previously and showed that normal healthy bone is very resistant to PDT effects in contrast to radiotherapy so inadvertent light exposure to bone is unlikely to cause necrosis.

PDT in combination with radiotherapy to treat bone metastases from breast cancer in an animal model has been studied recently [77]. Following radiotherapy alone the established spinal metastases were successfully eliminated. However rats also subjected to PDT in combination with radiotherapy also showed some evidence of improved trabecular structure. Quantitative histological examination suggested that PDT induced increases to bone to marrow ratio mainly due to the increased formation of newly formed woven bone 
and an increase in osteiod formation compared to rats treated with radiotherapy alone [77]. The authors concluded that while they were unable assess if PDT eliminated tumour cells in spinal metastases the process of induced tissue injury resulted in an inflammatory response as a part of healing. A further beneficial side effect was that the PDT treated areas showed reduced amounts of osteoclasts. Since radiotherapy usually causes an increase in osteoclasts and bone resorption, adjuvant treatment would reduce this potentially harmful effect of radiotherapy. The less desirable effects of combined therapy was that the cortical shell thickness of combined treatment areas were significantly thinner, but this did not translate into observable measures of mechanical bone weakness; in fact bone-mineral density and bone volume was increased [76]. Crucially this study could not establish that PDT in an adjuvant setting with radiotherapy improved the outcome of treatment for spinal metastases in the short term. However in the long term some of the changes induced by PDT may have resulted in improved recovery from treatment. Subsequently the same group recently published their findings after evaluation of rat vertebrae 6 weeks after being treated with PDT [77]. This randomised study demonstrated that PDT appeared to improve vertebral integrity in combination with bisphosphonates or radiotherapy suggesting its potential use in adjuvant treatment of spinal metastases [78]. Translation of this work into the clinical setting for breast cancer is awaited.

In the setting of adjuvant chemotherapy, PDT also has potential applications. Photosensitisers can be used in combination with chemotheraputic agents by photochemical internalisation (PCI) [79-81]. Macromolecular chemotheraputic agents, 
which are subject to endolysosomal sequestration, can be released into the cytosol by this method by activation of the photosensitiser which is localised in endolysosomal membranes owing to their amphiphilic properties. This allows selective targeting of tumour cells since release of the endocytosed agents to their intended intracellular targets occurs within the illuminated area [79]. This is another area that requires clinical research to validate its use in breast cancer.

\section{PDT compared to other treatment modalities}

A full discussion of all new technologies emerging of the treatment of breast cancer in comparison to PDT is beyond the remit of this review. However there are a few treatments, which have been considered as future breast cancer treatments. High intensity focused ultrasound (HIFU) and Radio frequency ablation (RFA) are two of the most promising rivals to PDT. HIFU relies on the same technical principles as conventional ultrasound, however unlike diagnostic ultrasound, HIFU the intensity of HIFU in the focal region is several orders higher [82]. HIFU induces coagulative necrosis caused by heat with giant cell reaction with chronic inflammation the surrounding normal fatty tissue frequently shows histological signs of fat necrosis. HIFU is associated with an immune response resulting in apoptosis. In vitro studies show increases in heat shock protein HSP70, rise in circulating T lymphocytes but in contrast to PDT there is greater ratio of $C D 4+$ to $C D 8+T$ cells. So far there have been two clinical studies assessing its efficacy in breast cancer $[83,84]$; although HIFU had 5 year disease free survival of $95 \%$, both studies were small with less than 50 patients in total. Long term effects of HIFU are unknown, 2 patients in the studies had skin burns and the inability to assess margins by histopathology is a significant limitation compared to standard 
treatment. In addition in contrast to PDT no evidence has been presented that it results in a sustained adoptive immune response. Radio frequency ablation (RFA) uses a radiofrequency electrode combined with CT or ultrasound to heat and coagulate tissue [85]. Immune response related to RFA has been studied, and serum levels of pro-inflammatory cytokines were either increased or unchanged with modest transient changes $[86,87]$. In vivo murine studies have shown that there is increase expression of HSP, T cell activation with proliferation of CD4+ and CD8+ populations and tumour specific antibodies [86]. Furthermore adaptive transfer has been demonstrated in vivo as in PDT [88]. A review of 25 clinical studies consisting of 400 patients using RFA to treat breast cancer has been performed and have shown high efficacy [85]. However their results are difficult to interpret due to their heterogeneous inclusion criteria and use of RFA as primary or secondary procedure. Burns were significant major complications occurring in a small number of patients in the majority of these studies [85]. Finally while there has been no formal comparison of conventional primary treatments (surgery, chemotherapy, radiotherapy or endocrine therapy) to PDT so far. However in 2014 Spratt et al [89], published a metaanalysis of treatments for cutaneous metastases almost all from melanoma and breast cancer. This included PDT treatment and the results for objective response showed equivalence with radiotherapy.

\section{PDT and clinical applications in breast cancer treatment}

The first clinical application for this technology in breast cancer treatment was in the treatment of skin metastases in chest wall recurrence [90-94]. 
The initial series of 37 patients with breast carcinoma chest wall recurrence treated with PDT by Khan et al in 1993 [93] (Table 1) showed that this was an effective treatment in selected patients although there was a variation in the extent of response. Photofrin was used as the photosensitiser in this light dose escalation study to determine the minimal light dose at which there was an effective response. The results showed that 5 patients achieved a complete response, 13 demonstrated partial responses and 19 showed no benefit [93]. The extent and type, of recurrent disease, were strong determinants of the likelihood of response. Minimal and nodular disease responded well to PDT; partial responses were seen in patients with disease of moderate extent. A phase I study evaluating mono-L-aspartyl chlorin e6 (Npe6). In a dose escalation study was conducted by Taber et al [91], while there were no systemic adverse effects, all patients experienced transient generalised skin photosensitivity and light treatment caused immediate tissue blanching indicating vascular shutdown [91]. Marked necrosis of the tumor mass was observed and regression of tumor occurred between 1-2 days post treatment with formation of an eschar over the tumour site. However re-epithelialisation occurred under the eschar and complete healing occurred in 8-12 weeks. The study was also not selective for breast cancer recurrence as only 4 of the 11 patients in the study having cutaneous breast metastases. The authors found that although tumour regression occurred 1 out of 3 patients its effect was incomplete. Tumour re-growth occurred on the edges at the interphase between tumour and normal skin. the optimum dose to control tumour re-growth was between 2.5 or $3.5 \mathrm{mg} / \mathrm{kg}$ combined with $100 \mathrm{~J} / \mathrm{cm} 2$ of light energy with 6 of 9 of sites which showed complete response, remaining tumor-free through 12 weeks observation [91]. 
Wyss et al treated breast cancer chest wall recurrence in 7 patients with complete response [94]. In this short series the photosensitizer meta-tetra (hydroxyphenyl) chlorin (m-THPC), was injected intravenously. Response to treatment did not differ when using the 2 different drug dose protocols. Healing time depended mainly on the size of the illumination field but not on the light dose. Similarly Cuenca et al found that PDT was an effective treatment for the palliation of chest wall recurrence using Photofrin [92]. 500 separate cutaneous truncal lesions were treated in 14 patients [92]. The follow up period ranged from 6 to 24 months. While all patients demonstrated tumour necrosis and 9 out of 14 had complete responses and several had regression of untreated lesions there was no effect on disease progression. Li et al in 2011 combined PDT with immune therapy with a trial assessing safety and efficacy of laser immunotherapy (LIT) for the treatment of metastatic breast cancer[95]. All 10 patients who were enrolled had either stage 3-4 disease and 8 patients were suitable for final evaluation [95]. Only 1 patient had complete response; 4 patients had partial response, 2 maintained stable disease and 2 patients with disease progression [95]. There was transient thermal injury, whose prolonged duration was strongly associated with previous radiotherapy. However there were no serious adverse effects or deaths due to this treatment. While the application of immunotherapy to treat cancers is not new this study demonstrated that adjuvant treatment with immunotherapy following PDT may improve its effectiveness and represents a viable future treatment of tumours at distant sites. Finally the first phase I/Ila clinical trial of PDT in the treatment of primary breast cancer is underway in the UK (see table 1) with preliminary results expected at the end of 2016 
(unpublished comunication). If this trial is successful and the treatment is well tolerated this will open the door to much needed clinical investigation in PDT.

\section{Discussion}

PDT in breast cancer is still at preliminary stages of research. However, its low toxicity, repeatability and potential immunological effects suggest it to be suitable as a treatment modality for breast cancer. Translating the advances made in understanding the effects of PDT in the cell line based studies and animal models into clinical practice, is the current challenge for this treatment. Current conventional breast cancer treatment options are successful and set a high bar for novel treatment strategies which need to offer at least equal efficacy if not show additional advantages to be accepted as suitable treatment. The scientiflc evidence is mounting in favour of PDT as such a treatment modality. However so far, it has only been used as trial treatment of cutaneous metastasis in patients with advanced disease. The next uncharted territory is whether treatment of the primary breast cancer with PDT might result in a more effective treatment strategy. This is particularly pertinent as investigations into the immunomodulatory effects of PDT suggest at least in animal models that it stimulates the host immune system to facilitate tumour cell death and prevent tumour growth and spread $[48,49,50]$. Further clinical research may perhaps lead to PDT being considered as a method of vaccination against tumours [96]. This clearly would be of great advantage as PDT treatment in patients treated for primary breast cancer could also result in acquired immunity against the cancer at distant sites for all metastases of the same tumour clone. Under these circumstances, its current position as a potential 
complimentary adjuvant therapy could be extended to become a standard of care in breast cancer treatment. Further research is required if PDT is to be used successfully in primary breast cancer. 


\section{TABLE 1: Photosensitisers (PS) investigated for use in breast cancer treatment}

\begin{tabular}{|c|c|c|c|c|}
\hline PS & $\begin{array}{l}\text { Wave } \\
\text { Length } \\
(\mathrm{nm})\end{array}$ & $\begin{array}{l}\text { Time to PDT } \\
\text { After } \\
\text { Dose } \\
\text { Delivery }\end{array}$ & Study & Properties/uses/delivery [64] \\
\hline $\begin{array}{l}\text { Zinc } \\
\text { phthalo- } \\
\text { cyannine }\end{array}$ & 675 & 12 hours & $\begin{array}{l}\text { In- vitro } \\
\text { Study on murine } \\
\text { breast cancer cell } \\
\text { lines [29] }\end{array}$ & $\begin{array}{l}2^{\mathrm{ND}} \text { generation PS } \\
\text { Liposomal preparation } \\
\text { administered intravenously. } \\
\text { Insoluble in water. } \\
\text { Not currently used in clinical } \\
\text { trials }\end{array}$ \\
\hline $\begin{array}{l}\text { SnEt2 } \\
\text {-Purlytin }\end{array}$ & 660 & 24 hours & $\begin{array}{l}\text { Clinical use for } \\
\text { Treatment of skin } \\
\text { metastases } \\
\text { including breast } \\
\text { cancer } \\
\text { [33] }\end{array}$ & $\begin{array}{l}2^{\mathrm{ND}} \text { generation PS. } \\
\text { Intravenous adminstration } \\
\text { Used in Phase II clinical trials } \\
\text { Localized in skin. Used in } \\
\text { clinical treatment. 7-14 days } \\
\text { post administration Photo- } \\
\text { sensitivity can occur. }\end{array}$ \\
\hline $\begin{array}{l}\text { Motexafin } \\
\text { lutetium } \\
\text { (Lutex) }\end{array}$ & 720 & $3-24$ hours & $\begin{array}{l}\text { Clinical use for } \\
\text { Treatment of skin } \\
\text { metastases } \\
\text { including breast } \\
\text { cancer } \\
\text { [31] }\end{array}$ & $\begin{array}{l}2^{\mathrm{ND}} \text { generation PS } \\
\text { water soluble agent } \\
\text { intravenous administration. } \\
\text { Used in phase I clinical trial } \\
\text { for prostate cancer and } \\
\text { treatment of psoriasis. Low } \\
\text { incidence of photosensitivity }\end{array}$ \\
\hline Photofrin & 630 & 48 hours & $\begin{array}{l}\text { Clinical Trial for the } \\
\text { treatment of breast } \\
\text { cancer skin } \\
\text { metastases [93] }\end{array}$ & $\begin{array}{l}1^{\text {st }} \text { generation PS derivative } \\
\text { lipophilic agent. Intravenous } \\
\text { administration. } 4-12 \text { weeks } \\
\text { Risk of Photosensitivity. }\end{array}$ \\
\hline $\begin{array}{l}\text { mono-L- } \\
\text { aspartyl } \\
\text { chlorin }\end{array}$ & $664-667$ & 4 hours & $\begin{array}{l}\text { Clinical trial for the } \\
\text { treatment of breast } \\
\text { cancer skin } \\
\text { metastases [91] }\end{array}$ & $\begin{array}{l}2^{\text {nd }} \text { generation PS derivative } \\
\text { intravenous administration. } \\
\text { Soluble in sodium chloride } \\
\text { solution. Photosensitivity risk } \\
\text { for up to } 3 \text { weeks. }\end{array}$ \\
\hline $\begin{array}{l}\text { meta-tetra } \\
\text { (hydroxyphe } \\
\text { nyl) chlorin } \\
\text { (m-THPC) } \\
\text { (Foscan) }\end{array}$ & 652 & 48-96 hours & $\begin{array}{l}\text { Patient series } \\
\text { treatment of breast } \\
\text { cancer metastases } \\
{[92]}\end{array}$ & $\begin{array}{l}2^{\mathrm{ND}} \text { generation PS } \\
\text { insoluble in aqueous solution. } \\
\text { Intravenous administration. } \\
\text { Used in treatment of head } \\
\text { and neck, squamous cell } \\
\text { carcinoma and lung cancers.2- } \\
6 \text { weeks photosensitivity risk. }\end{array}$ \\
\hline $\begin{array}{l}\text { Verteporfin } \\
\text { (Visudyne) }\end{array}$ & 690 & 1 hour & $\begin{array}{l}\text { Clinical Trial for } \\
\text { treatment in } \\
\text { primary breast } \\
\text { cancer* used in } \\
\text { murine breast } \\
\text { cancer models } \\
{[23,31,32]}\end{array}$ & $\begin{array}{l}2^{\mathrm{ND}} \text { generation PS } \\
\text { Liposomal preparation. } \\
\text { Intravenous administration } \\
\text { Licensed for treatment of } \\
\text { macular degeneration. Low } \\
\text { incidence of photosensitivity }\end{array}$ \\
\hline
\end{tabular}

* Trial ongoing at Royal Free London NHS foundation trust since 2013 trial outcome due end of 2016 (unpublished communication). 
Acknowledgements:

Royal Free Charity, Killing Cancer, and the Javon Foundation for financial support. There was no involvement or input in the preparation or submission of this manuscript by the above mentioned charities.

Conflicts of interest: none

Ethical Approval was not required for this publication. 
FIGURE 1

PDT in breast cancer - the treatment process

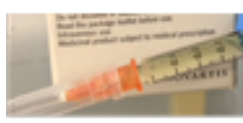

PS is given to patient int ravenously.

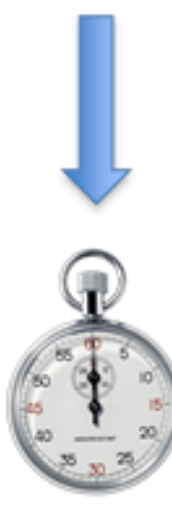

PS is distributed within vasculature and reaches optimum concentration within normal and tumour cells over time. The time this take depends on which PS is used.

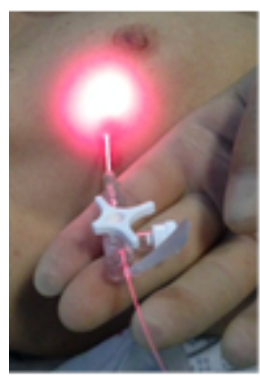

PDT is targeted into tumour or skin m et astases within end organ -the breast 
FIGURE 2 : The photochemical reactions resulting from PDT (Jablonski diagram)

The absorption of a photon of light by the photosensitiser leads to a photochemical reaction that elevates this photosensitizer molecule from its ground state $\left(\mathrm{S}_{0}\right)$ to an excited state $\left(\mathrm{S}_{1}\right)$. Subsequently the transition of the photosensitser from the singlet $S_{1}$ state to the triplet $T_{1}$ excitable state allows the photosensitiser to transfer this energy to an oxygen molecule transforming it to either reactive oxygen species (type I reaction) its highly reactive singlet state (type II reaction).

\section{Excited PS}

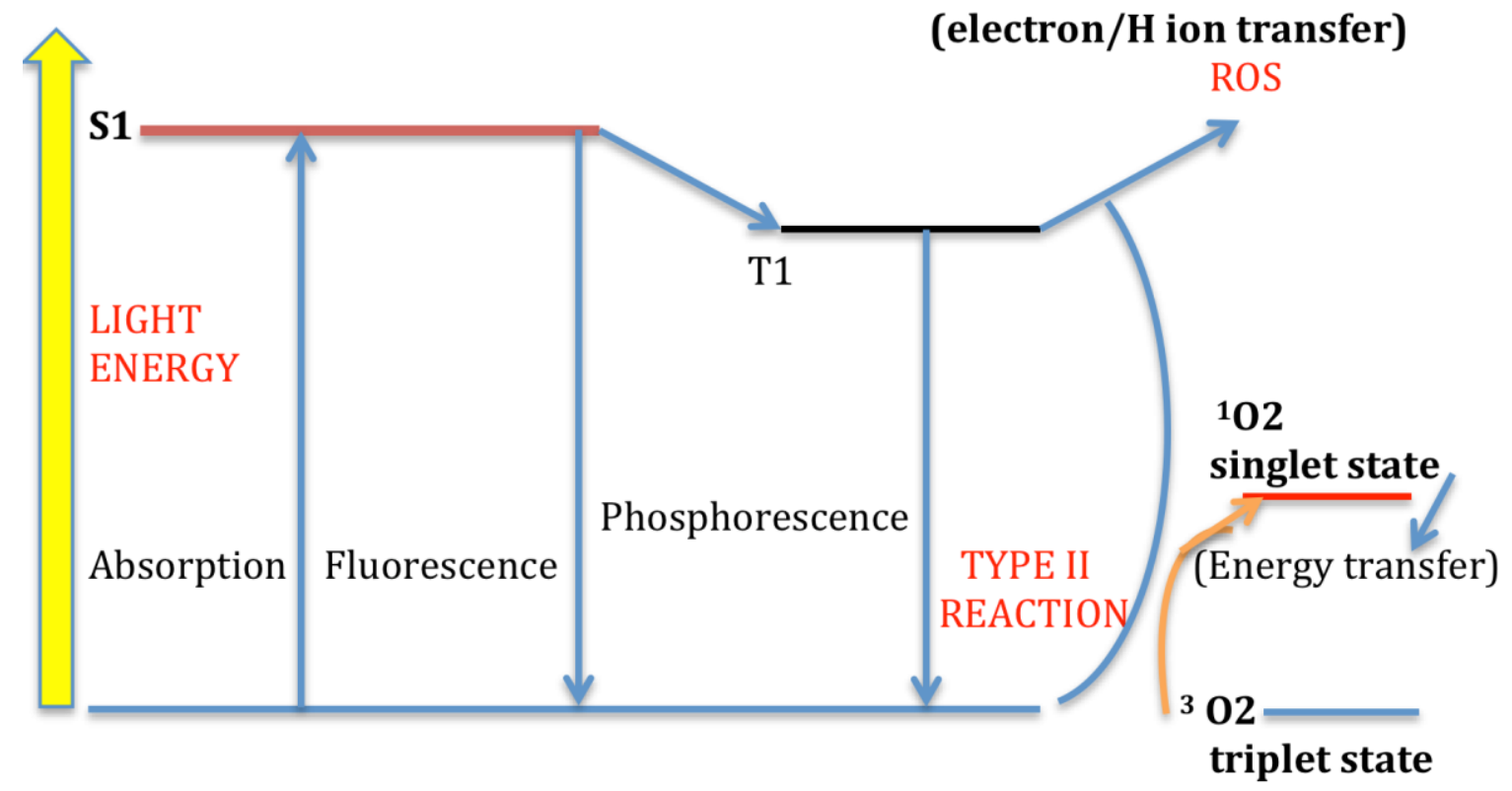

So

Ground state PS 


\section{FIGURE 3:}

PDT is usually applied at wavelengths of $600-800 \mathrm{~nm}[29,30]$. Across this range the major components of living tissue- water, haemoglobin in blood and protein has low absorption of light allowing its passage through them with minimal scatter. Shown below is the absorption spectrum for PDT which shows this range.

\section{ABSORPTION SPECTRUM FOR PDT}

ABSORPTION

\section{CO-EFFICIENT $\left(\mathrm{cm}^{-1}\right)$}

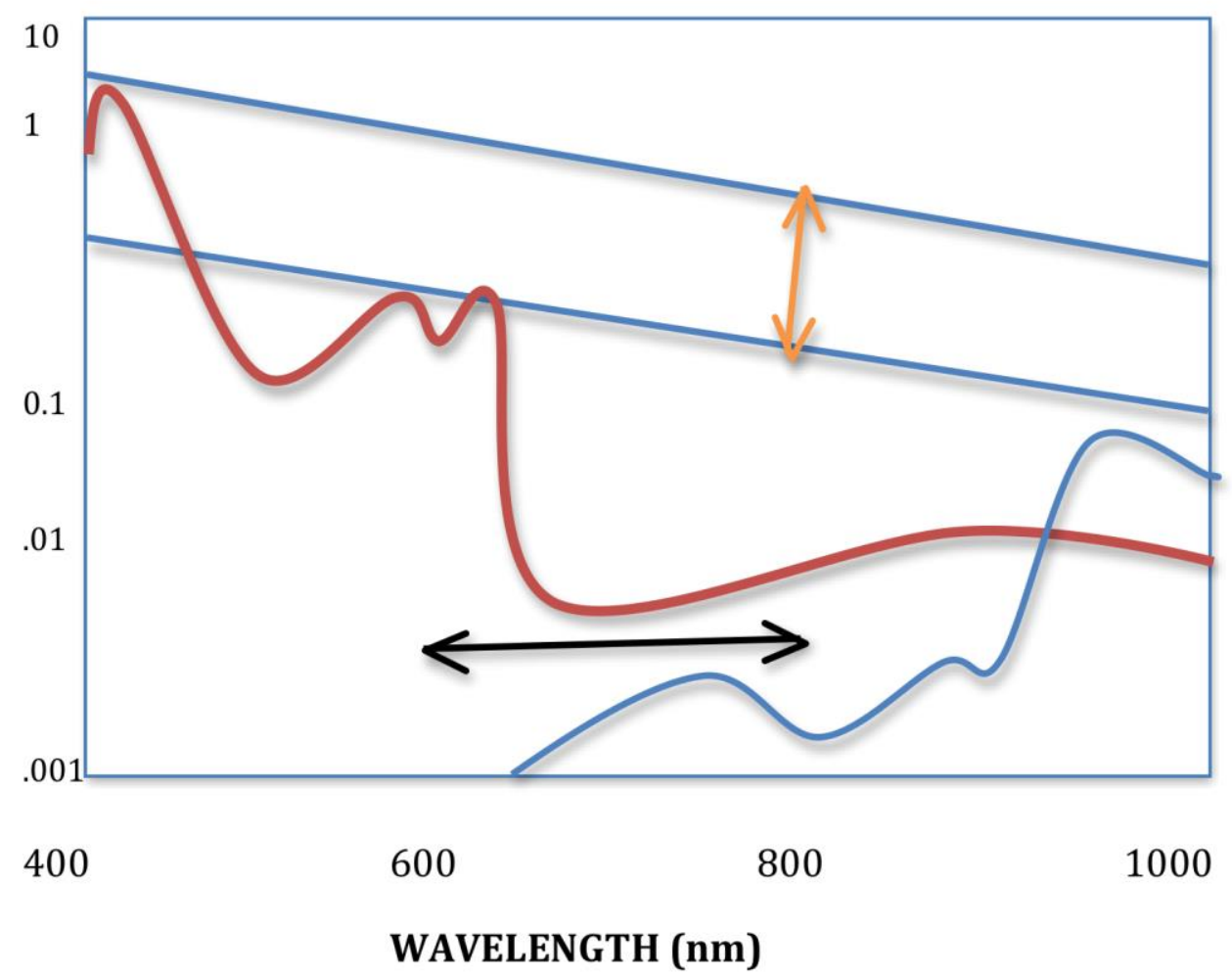

SCATTER ; OPTIMAL WAVELENGTH FOR TREATMENT 
FIGURE 4: Shows the relative penetration of light at different wavelengths with blue light being the least able to penetrate tissues while infra-red light is best for tissue penetration at depth.

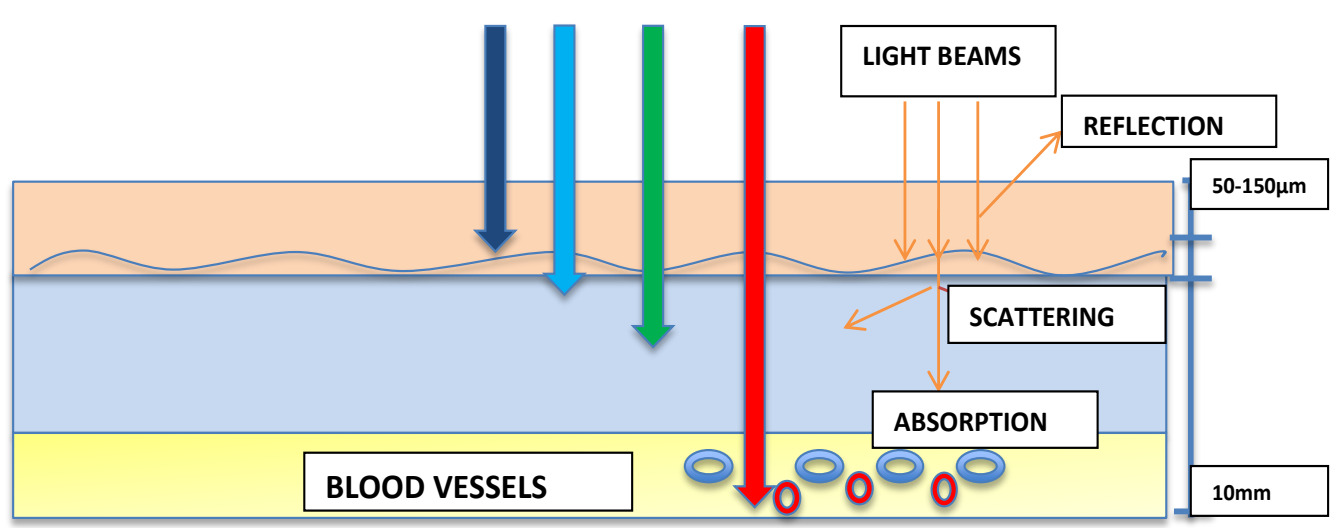


FIGURE 5 : DIAGRAM SHOWING THE CELL MEDIATED AND CYTOKINE RELATED IMMUNE RESPONSE FOLLOWING PDT LEADING TUMOUR SPECIFIC CYTOTOXICITY

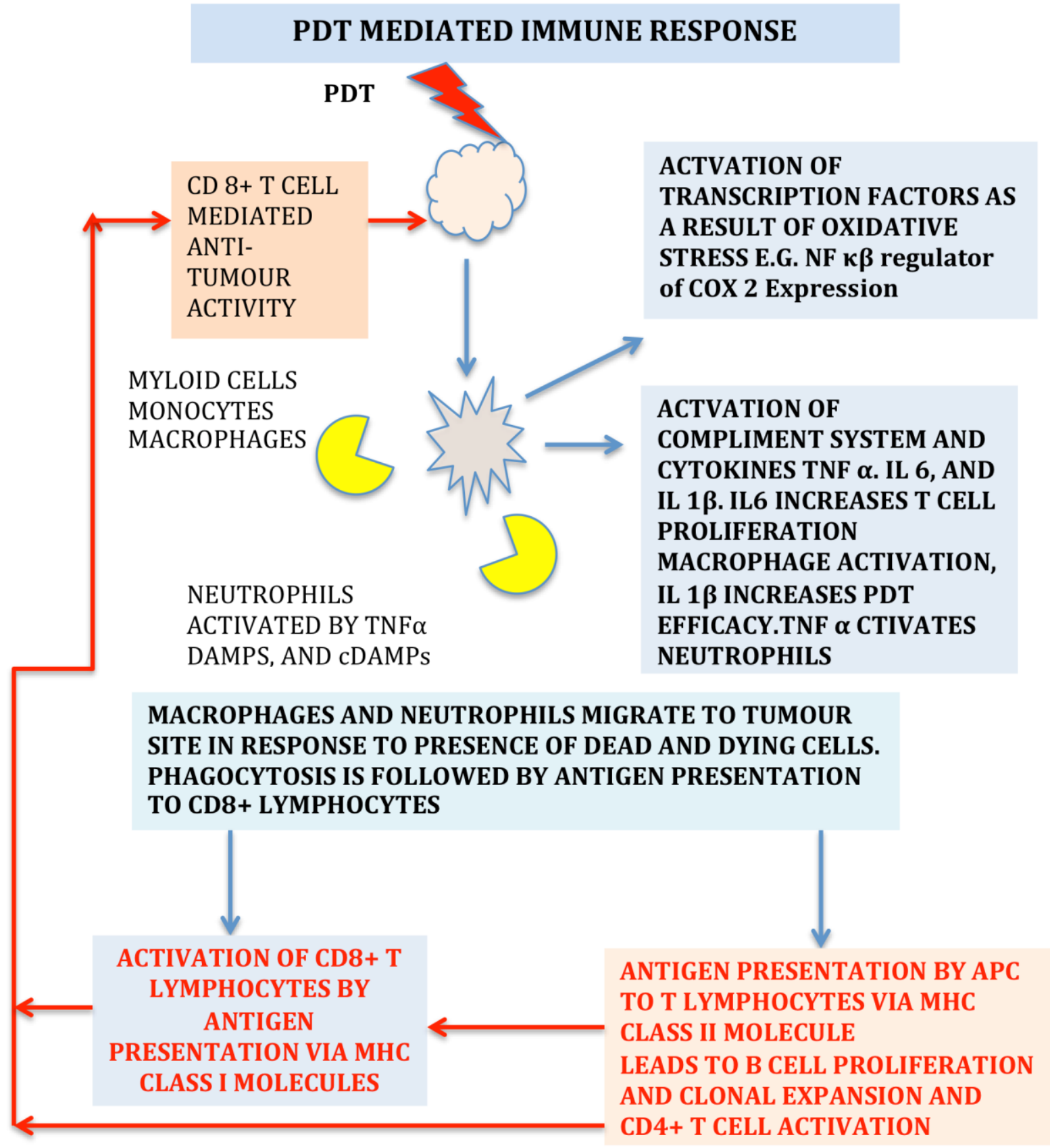




\section{REFERENCES:}

1. WHO methods and data sources for country-level causes of death 2000-2012 http://www.who.int/gho/mortality_burden_disease/en/index.html

2. De Santis C, Ma J, Bryan L, Jemal A. Breast Cancer Statistics 2013. CA Cancer J Clin. 2014;64 :52-62.

3.Veronesi U, Boyle P, Goldhirsch A, Orecchia R, Viale G. Breast Cancer. Lancet 2005; 365: 1727-41

4. Coleman MP, Quaresma M, Berrino F, Lutz J-M, Roberta De Angelis R, Riccardo Capocaccia $R$ et al. Cancer survival in five continents: a worldwide population-based study (CONCORD). Lancet Oncol .2008. 9; 730-56.

5. Data were provided by the Office for National Statistics on request, March 2013. http://www.ons.gov.uk/ons/publications/all-releases.html?definition=tcm\%3A77-27475.

6. Josefsen LB and Boyle RW. Photodynamic Therapy and the Development of Metal-Based Photosensitisers. Metal-Based Drugs. Volume 2008, Article ID 276109,23 pages. doi:10.1155/2008/276109

7. Nyman E.S. and Hynninen PH. Research advances in the use of tetrapyrrolic photosensitizers for photodynamic therapy. Journal of Photochemistry and Photobiology. 2004.vol. 73, no. 1-2, pp. 1-28

8. Agostinis P, Berg K, Keith, Cengel KA, Foster TH, Girotti AW, Gollnick SO, et al. Photodynamic Therapy of Cancer: An Update. CA CANCER J CLIN.2011; 61:250-281

9. Wilson BC and Patterson MS. Photodynamic Therapy of Neoplastic Disease, edited by D. Kessel CRC Press, Boca Raton. 1990. Vol. 1,pp. 129-144.

10. P. Mroz and M. R. Hamblin, The immunosuppressive side of PDT, Photochem. Photobiol. Sci., 2011, 10, 751. 
11. Allison RR, Mota HC, and Sibata CH . Clinical PD/PDT in North America: an historical review. Photodiagnosis and Photodynamic Therapy. 2004.vol. 1, no. 4, pp. 263-277.

12. Dougherty TJ, Gomer CJ, Henderson BW, Jori G, Kessel D, Korbelik M et al. Photodynamic therapy. Journal of the National Cancer Institute. 1998. vol. 90, no. 12, pp. 889-905, 1998

13. Cl 'o E, Snyder JW, Ogilby PR, and Gothelf KV, Control and selectivity of photosensitized singlet oxygen production: challenges in complex biological systems. ChemBioChem. 2007. vol. 8, no. 5, pp. 475-481.

14. Snyder JW, Skovsen E, Lambert JDC, Poulsen L, and Ogilby PR, Optical detection of singlet oxygen from single cells. Physical Chemistry Chemical Physics.2006.vol. 8, no. 37, pp.4280-4293.

15. Skovsen E, Snyder JW, Lambert JDC, and Ogilby PR. Lifetime and diffusion of singlet oxygen in a cell. Journal of Physical Chemistry B. 2005.vol. 109, no. 18, pp. 8570-8573, 2005

16. Castano AP, Demidova TN, and Hamblin MR. Mechanisms in photodynamic therapy: part one-photosensitizers, photochemistry, and cellular localization. Photodiagnosis and Photodynamic Therapy.2004. vol. 1, no. 4, pp. 279-293.

17. Lang K, Mosinger J, and Wagnerov'a DM. Photophysical properties of porphyrinoid sensitizers non-covalently bound to host molecules; models for photodynamic therapy. Coordination Chemistry Reviews.2004.vol. 248, no. 3-4, pp. 321-350,

18.E. Weizman, C. Rothmann, L. Greenbaum, Shainberg A, Adamek M, Ehrenberg B et al., "Mitochondrial localization and photodamage during photodynamic therapy with tetraphenylporphines. Journal of Photochemistry and Photobiology B. 2000.Vol. 59, no. 1-3, pp. 92-102, 2000.

19. M. Oschner. Photophysical and photobiological processes in the photodynamic therapy of tumours. Journal of Photochemistry and Photobiology B. Vol. 39, no. 1, pp. 1-18, 1997

20. Morgan J and Oseroff AR. Mitochondria-based photodynamic anti-cancer therapy. Advanced Drug Delivery Reviews. 2001. Vol. 49, no. 1-2, pp. 71-86

21. Bonnett R. Photosensitizers of the porphyrin and phthalocyanine series for photodynamic therapy. Chemical SocietyReviews. 1995. Vol. 24, pp. 19-33

22. S. B. Brown, E. A. Brown, and I. Walker. The present and future role of photodynamic therapy in cancer treatment. Lancet Oncology. 2004. Vol. 5, no. 8, pp. 497-508 
23. Detty MR, Gibson SL, and Wagner SJ. Current clinical and preclinical photosensitizers for use in photodynamic therapy. Journal of Medicinal Chemistry. 2004. Vol. 47, no. 16, pp. 3897-3915, 2004.

24. Lo PC, Leung SCH, Chan EYM, Fong WP, Ko W-H, and Ng DNP. Photodynamic effects of a novel series of silicon(IV) phthalocyanines against human colon adenocarcinoma cells. Photodiagnosis and Photodynamic Therapy. 2007. Vol. 4, no. 2, pp. 117-123

25. George JE, Ahmad Y, Varghai D, Xiaolin L, Berlin J, Jackowe D et al. PC4 photodynamic therapy of U87-derived human glioma in the nude rat. Lasers in Surgery and Medicine. 2005. Vol. 36, no. 5, pp. 383-389

26. Whitacre CM, Satoh TH, Xue L-Y, Gordon NH, and Oleinick NL. Photodynamic therapy of human breast cancer xenografts lacking caspase-3. Cancer Letters. 2002. Vol. 179, no. 1, pp. 43-49.

27. Fabris C, Soncin M, Miotto G, Fantetti L, Chiti G, Dei D et al. Zn(II)- phthalocyanines as phototherapeutic agents for cutaneous diseases. Photosensitization of fibroblasts and keratinocytes. Journal of Photochemistry and Photobiology B. 2006. Vol. 83, no. 1, pp. 4854

28. V. Mantareva, V. Kussovski, I. Angelov, Borisova E, Avramov L, Schnurpfeil G,et al. Photodynamic activity of water-soluble phthalocyanine zinc(II) complexes against pathogenic microorganisms. Bioorganic \& Medicinal Chemistry. 2007.Vol. 15, no. 14, pp. 4829-4835

29. Mfouo-Tynga I, Houreld NN, and Heidi Abrahamse. Induced Cell Death Pathway Post Photodynamic Therapy Using a Metallophthalocyanine Photosensitizer in Breast Cancer Cells. Photomedicine and Laser Surgery 2014 Vol 32 ; 4:205-211

30. Portilho FA, Cavalcanti CE, Miranda-Vilela AL, Estevanato LL, Longo JP, Almeida Santos Mde $\mathrm{F}$ et al. Antitumor activity of photodynamic therapy performed with nanospheres containing zinc-phthalocyanine. J Nanobiotechnology. 2013 Dec 16;11:41

31. MacDonald IJ and Dougherty TJ. Basic principles of photodynamic therapy. Journal of Porphyrins and Phthalocyanines. 2001.Vol. 5, no. 2, pp. 105-129.

32. Levy JG, Jones CA, and Pilson LA.The preclinical and clinical development and potential application of benzo- porphyrin derivative. International Photodynamic Therapy. 1994.Vol. 1, pp. 3-5.

33. Bonnett R and Martinez G. Photobleaching of sensitisers used in photodynamic therapy. Tetrahedron. 2001. Vol. 57, no. 47,pp. 9513-9547 
34. Andreoni A, Colasanti A, Roberti G. Excited singlet state properties of anthracenedione photosensitizers. J Photochem Photobiol B .1992;14:319-28.

35. Hartley JA, Forrow SM, Souhami RL, Reszka K. Photosensitiza- tion of humanvleukemic cells by anthracenedione antitumor agents. Cancer Res. 1990;50:1936-41.

36. Montazerabadi A-R, Sazgarnia A, Bahreyni-Toosi MH, Ahmadi A, Shakeri-Zadeh A, Aledavood A. Mitoxantrone as a prospective photosensitizer for photodynamic therapy of breast cancer . Photodiagnosis and Photodynamic Therapy. 2012. 9, 46-51.

37.Lanks KW, Gao J-P, Sharma T. Photodynamic enhancement of doxorubicin cytotoxicity. Cancer Chemother Pharmacol .1994.35:17-20.

38.Secret E, Maynadier M, Gallud A, Gary-Bobo M, Chaix A, Belamie E et al. Anionic porphyrin-grafted porous silicon nanoparticles for photodynamic therapy. Chem. Commun. $2013,49,4202$.

39.Shemesh CS, Hardy CW, Yu DS, Fernandez B, Zhang H. Indocyanine green loaded liposome nanocarriers for photodynamic therapy using human triple negative breast cancer cells. Photodiagnosis Photodynamic therapy. 2014. June;11(2):193-203.

40. Khanal A, Bui M-P N, Seo SS. Microgel-Encapsulated Methylene Blue for the Treatment of Breast Cancer Cells by Photodynamic Therapy. J Breast Cancer. 2014.17(1):18-24.

41. Matsumura $\mathrm{Y}$, Maeda $\mathrm{H}$. A new concept for macromolecular thera-peutics in cancer chemotherapy: mechanism of tumoritropic accumu-lation of proteins and the antitumor agent smancs. Cancer Res. 1986;46 (12 Pt 1):6387-92.

42. Maeda $\mathrm{H}$. The enhanced permeability and retention (EPR) effect in tumor vasculature: the key role of tumor-selective macromolecular drug targeting. Adv Enzyme Regul 2001;41:189-207.

43. Grabstain V, Bianco-Peled $\mathrm{H}$. Mechanisms controlling the temperature-dependent binding of proteins to poly(N-isopropylacrylamide) micro gels. Biotechnol Prog 2003;19:1728-33.

44.Azzouzi A-R, Barret E, Moore CM, Villers A, Allen C, Scherz A et al. TOOKAD ${ }^{\circledR}$ Soluble vascular-targeted photodynamic (VTP) therapy: determination of optimal treatment conditions and assessment of effects in patients with localised prostate cancer. BJU Int 2013; 112: 766-774 
45. Ueno T, Toi M, Koike M, Nakamura S, Tominaga T et al. Tissue factor expression in breast cancer tissues: its correlation with prognosis and plasma concentration. Br J Cancer 2000; 83; $164-170$.

46. Hu Z, Rao B, Chen S, Duanmo J. Targeting tissue factor on tumor cells and angiogenic vascular endothelial cells by factor VII-targeted verteporfin photodynamic therapy for breast cancer in vitro and in vivo in mice. BMC Cancer. 2010; 10: 235.

47.Duanmu J, Cheng J, Xu J, Booth CJ, Hu Z et al. Effective treatment of chemoresistant breast cancer in vitro and in vivo by a factor VII targeted photodynamic therapy. Br J Cancer 2011. 104; 1401-1409.

48. Anzengruber F, Avci P, Freitas de Freitas $L$ and Hamblin MR. T-cell mediated anti-tumor immunity after photodynamic therapy: why does it not always work and how can we improve it? Photochem. Photobiol. Sci., 2015, 14, 1492

49. WachoWska M, MuchoWicz A, DeMkoW U. Immunological aspects of antitumor photodynamic therapy outcome. Central European Journal of Immunology 2015; 40(4)

50. Brodin NP, Guha C, and Tome WA. Photodynamic Therapy and Its Role in Combined Modality Anticancer Treatment. Technology in Cancer Research \& Treatment 2015, Vol. 14(4) 355-368.

51. Sun SC and Xiao G. Deregulation of NF-kappaB and its upstream kinases in cancer, Cancer Metastasis Rev., 2003, 22, 405.

52. Baeuerle PA and Henkel T. Function and activation of NF-kappa B in the immune system. Annu. Rev. Immunol., 1994, 12, 141.

53. Cecic I, Stott B and Korbelik M, Acute phase response- associated systemic neutrophil mobilization in mice bearing tumors treated by photodynamic therapy, Int. Immunopharmacol., 2006, 6, 1259.

54. Krosl G, Korbelik M and Dougherty GJ, Induction of immune cell infiltration into murine SCCVII tumour by photofrin-based photodynamic therapy, Br. J. Cancer, 1995, 71, 549.

55.Wachowska M, Gabrysiak M, Muchowicz A, Bednarek W, Barankiewicz J, Rygiel T et al. 5-Aza-20-deoxycytidine potentiates antitumour immune response induced by photodynamic therapy. European Journal of Cancer. 2014. 50; 1370-1381 
56.Castano AP, Mroz P and Hamblin MR, Photodynamic therapy and anti-tumour immunity, Nat. Rev. Cancer, 2006, 6, 535.

57.Mroz P, Hashmi JT, Huang Y-Y, Lange N and Hamblin MR. Stimulation of anti-tumor immunity by photodynamic therapy. Expert Rev. Clin. Immunol. 2011.7(1); 75-91

58. Korbelik $\mathrm{M}$ and Cecic I, Complement activation cascade and its regulation: relevance for the response of solid tumors to photodynamic therapy, J. Photochem. Photobiol., B, 2008, $93,53$.

59. B. Stott and M. Korbelik, Activation of complement C3, C5, and C9 genes in tumors treated by photodynamic therapy, Cancer Immunol. Immunother., 2007, 56, 649.

60. Q. Q. Dou, A. Rengaramchandran, S. T. Selvan, R. Paulmurugan and Y. Zhang, Core - shell upconversion nanoparticle - semiconductor heterostructures for photo- dynamic therapy, Sci. Rep., 2015, 5, 8252.

61.Musser DA, Camacho SH, Manderscheid PA and Oseroff AR. The anatomic site of photodynamic therapy is a determinant for immunosuppression in a murine model, Photochem. Photobiol., 1999, 69, 222.

62. Reddan JC, Anderson CY, Xu H, Hrabovsky S, Freye $\mathrm{K}$ et al Immunosuppressive effects of silicon phthalocyanine photodynamic therapy, Photochem. Photobiol., 1999, 70, 72.

63. Coutier S, Bezdetnaya LN, Foster TH, Parache RM and Guillemin F, Effect of irradiation fluence rate on the efficacy of photodynamic therapy and tumor oxygenation in meta-tetra (hydroxyphenyl ) chlorin (mTHPC)-sensitized HT29 xenografts in nude mice, Radiat. Res., 2002, 158, 33

64.Ruud Weijera R, Mans Broekgaardena M, Kosa M, van Vughtb R, Rauwsc EAJ, Eefjan Breukinkb E, van Gulika TM, Gert Stormd G, Heger M. Enhancing photodynamic therapy of refractory solid cancers: Combining second-generation photosensitizers with multi-targeted liposomal delivery. Journal of Photochemistry and Photobiology C: Photochemistry Reviews 23 (2015) 103-131

65.Chen J, Wang J, Xi L, Au L, Siekkinen A, Warsen A et al. Immuno gold nanocages with tailored optical properties for targeted phototermal destruction of cancer cells. Nano Lett 2007; 7: 1318-1322. 
66. Bhowmick R and Girotti AW. Rapid Upregulation of Cytoprotective Nitric Oxide in Breast Tumor Cells Subjected to a Photodynamic Therapy-like Oxidative Challenge. Photochemistry and Photobiology.2011, 87: 378-386

67. Song J, Wei Y, Chen Q, Xing D. Cyclooxygenase 2 mediated apoptotic and inflammatory responses in photodynamic therapy treated breast adenocarcinoma cells and xenografts. $J$ Photochem Photobiol B. 2014.134:27-36

68. Zou W, Immunosuppressive networks in the tumour environment and their therapeutic relevance, Nat. Rev. Cancer, 2005, 5, 263.

69.J Alili A, Makowski M, Switaj T, Nowis D, Wilczynski GM, et al. Effective photoimmunotherapy of murine colon carcinoma. induced by the combination of photodynamic therapy and dendritic cells, Clin. Cancer Res., 2004, 10, 4498.

70. Mohammadpour H, Majidzadeh K . Antitumor effect of conditioned media derived from murine MSCs and 5-aminolevulinic acid (5-ALA) mediated photodynamic therapy in breast cancer in vitro. Photodiagnosis and Photodynamic Therapy .2015. 12, 238-243

71. Korbelik M, Sun J, Posakony JJ. Interaction between photodynamic therapy and BCG immunotherapy responsible for the reduced recurrence of treated mouse tumors. Photochem Photo- biol. 2001;73(4):403-409.

72. Xia Y, Gupta GK, Castano AP, Mroz P, Avci P, and Hamblin MR. 4 CpG oligodeoxynucleotide as immune adjuvant enhances photodynamic therapy response in murine metastatic breast cancer J. Biophotonics. 2014. 7, No. 11-12, 897-905.

73. Shams M Owczarczak B ,Manderscheid-Kern P, Bellnier DA , Gollnick SO. Development of photodynamic therapy regimens that control primary tumor growth and inhibit secondary disease. Cancer Immunol Immunother (2015) 64:287-297

74.Mehta MP, Shapiro WR, Glantz MJ, Pathchell RA, Weitzner MA, Meyers CA et al. Lead-in phase to randomized trial of motexafin gadolinium and whole-brain radiation for patients with brain metastases: centralized assessment of magnetic resonance imaging, neurocognitive, and neurologic end points. J. Clin. Oncol. 2002.20(16); 3445-3453

75.Montazerabadi AR; Sazgarnia A; Bahreyni-Toosi MH; Ahmadi A and Aledavood A. The effects of combined treatment with ionizing radiation and indocyanine green-mediated 
photodynamic therapy on breast cancer cells. Journal of Photochemistry \& Photobiology, B: Biology.2012, Vol.109; pp.42-49

76. Meyer M, Speight P \& Bown SG. A study of the effects of photodynamic therapy on the normal tissues of the rabbit jaw. B J C .1991. 64; 1093-1097

77.Lo VCK ,Akens MK, Moore S, Yee AJM, Wilson BC, Whyne CM. Beyond radiation therapy: photodynamic therapy maintains structural integrity of irradiated healthy and metastatically involved vertebrae in a pre-clinical in vivo model. Breast Cancer Res Treat 2012. 135:391401.

78. Lo VC, Akens MK, Wise- Milestone L., Yee AJ, Wilson BC, Whyne CM. The benefits of photodynamic therapy on vertebral bone are maintained and enhanced by combination treatment with bisphosphonates and radiation therapy. J Orthop Res. 2013;31(9);1398-405

79. Allison RR. Photodynamic therapy: oncologic horizons. Future Oncol. 2014. 10(1); 123142

80.Berg K, Selbo PK, Prasmickaite L, Tjelle TE, Sandvig J, Moan K et al. Photochemical internalization: a novel technology for delivery of macromolecules into cytosol. Cancer Res. 1999.59(6), 1180-1183

81. Weyergang A, Selbo PK, Berstad ME, Bostad M, Berg K. Photochemical internalization of tumor-targeted protein toxins. Lasers Surg. Med. 2011. 43(7); 721-733

82. Zhou Y-F. High intensity focused ultrasound in clinical tumor ablation. World J Clin Oncol 2011 January $10 ; 2(1): 8-27$

83. Furusawa H, Namba K, Nakahara H, Tanaka C, Yasuda Y, Hirabara E, Imahariyama M, Komaki K. The evolving non- surgical ablation of breast cancer: MR guided focused ultrasound (MRgFUS). Breast Cancer 2007; 14: 55-58

84. Wu F, Wang ZB, Zhu H, Chen WZ, Zou JZ, Bai J,LiK Q, Jin CB, Xie FL, Su HB. Extracorporeal high intensity focused ultrasound treatment for patients with breast cancer. Breast Cancer Res Treat 2005; 92: 51-60

85.Tiffany Nguyen, Eleanor Hattery, Vijay P. Khatri. Radiofrequency ablation and breast cancer: a review. Gland Surgery 2014;3(2):128-135 
86. Haen S, Pereira LP, Salih HR, Hans-Georg R and Gouttefangeas C. More Than Just Tumor Destruction: Immunomodulation by Thermal Ablation of Cancer. Journal.Immun. Research. 2011. Article ID 160250, 19 pages. http://dx.doi.org/10.1155/2011/160250

87. M. Fietta, M. Morosini, I. Passadore et al., "Systemic inflammatory response and downmodulation of peripheral CD25+Foxp3+T-regulatory cells in patients undergoing radiofrequency thermal ablation for lung cancer," Human Immunology, vol. 70, no. 7, pp. 477-486, 2009.

88. M. H. M. G. M. den Brok MHMG, Sutmuller RPM, van der Voort R et al. In situ tumor ablation creates an antigen source for the generation of antitumor immunity. Cancer Research, vol. 64, no. 11, pp. 4024-4029, 2004.

89. Spratt DE, Gordon- Spratt, EA, Wu S, DeRosa A, Lee NY, Lacouture ME, and Barker CA. Efficacy of Skin-Directed Therapy for Cutaneous Metastases From Advanced Cancer: A Meta-Analysis. JCO.2014.55.4634.

90. Shishkova N, Kuznetsova O, Berezov T._Photodynamic Therapy for Gynecological Diseases and Breast Cancer. Cancer Biology and Medicine 2012: 9;9-17; 2095-3941.

91.Taber SW, Fingar VH, Coots CT, Weiman TJ. Photodynamic therapy using mono-L-aspartyl chlorin e6 (Npe6) for the treatment of cutaneous disease: a phase I clinical study. Clin Cancer Res 1998;4: 2741-2746.

92. Cuenca RE, Allison RR, Sibata C, Downie GH. Breast cancer with chest wall progression: treatment with photodynamic therapy. Ann Surg Oncol 2004; 11: 322-327.

93. Khan SA, Dougherty TJ, Mang TS. An evaluation of photodynamic therapy in the management of cutaneous metastases of breast cancer. Eur J Cancer 1993; 29A: 1686-1690.

94.Wyss P, Schwarz V, Dobler-Girdziunaite D, Homung R, Walt H, Degen A et al. Photodynamic therapy of locoregional breast cancer recurrences using a chlorine type photosensitizer. Int J Cancer. 2001; 93: 720-724. 
95.Li X, Ferrel GI, Guerra MC, , Hode T, Lunn J , Adalsteinsson O et al.Preliminary safety and efficacy results of laser immunotherapy for the treatment of metastatic breast cancer patients. Photochem Photobiol Sci 2011; 10: 817-821.

96.Gollnick SO, Vaughan L, Henderson BW. Generation of effective anti-tumor vaccines using photodynamic therapy. Cancer Res.2002. 62(6); 1604-1608 (2002). 